\title{
Long-term trends in solar radiation and the associated climatic factors over China for 1961-2000
}

\author{
F. Liang ${ }^{1,2}$ and X. A. Xia ${ }^{1}$ \\ ${ }^{1}$ Institute of Atmospheric Physics, Chinese Academy of Sciences, Beijing, 100029, China \\ ${ }^{2}$ Beijing Meteorological Bureau, Beijing, 100089, China
}

Received: 15 March 2005 - Revised: 15 August 2005 - Accepted: 9 September 2005 - Published: 14 October 2005

\begin{abstract}
Long-term trends in downwelling solar irradiance and associated climatic factors over China are studied in the paper. Decreasing trends in global and direct radiation are observed over much of China. The largest decrease occurs in South and East China (east of about $100^{\circ} \mathrm{E}$ and south of about $40^{\circ} \mathrm{N}$ ). The spatial pattern of observed trends in diffuse irradiance is complex and inhomogeneous. An intriguing aspect of trends in global and direct irradiance is the rather abrupt decrease in annual and seasonal mean values from 1978 onward. The decreasing trends in solar radiation in China did not persist into the 1990s. The spatial and temporal patterns of trends in sunshine duration are consistent with that of global and direct irradiance. A decreasing trend in rainy days is observed over much of China, which is in agreement with the secular trend in cloud amount. The fact that trends in cloud amount and solar radiation are quite similar suggests that the cloud amount is not the primary cause for the decrease in solar radiation. Visibility in the eastern part of China has deteriorated heavily as a result of the rapid increase in aerosol loading. The statistical analysis showed that atmospheric transmission under clear conditions decreased rapidly. These facts suggest that the rapid increase in aerosol loading should be one of the principle causes for the decrease in solar radiation. The observed diurnal temperature range decreases remarkably in China, which is closely related to the increase in aerosols. The effects of anthropogenic air pollutants on climate should be further studied and included in the simulation of climate and projection of climate scenario.
\end{abstract}

Keywords. Atmospheric composition and structure (Aerosol and particles; General or miscellaneous) - Meteorology and atmospheric dynamics (Radiative processes)
Correspondence to: F. Liang

(liangfeng@bjmb.gov.cn)

\section{Introduction}

A couple of studies show that the average amount of sunlight reaching the ground across the world has been reduced by about $10 \%$ from 1960 to 1990 . These include stations in Antarctica (Stanhill and Cohen, 1997), Australia (Stanhill et al., 1994), Israel (Stanhill and Ianetz, 1996), Ireland (Stanhill, 1998), Germany (Liepert et al., 1997), the United States (Liepert et al., 2002), and the former Soviet Union (FSU) (Abakumova et al., 1996). Gilgen et al. (1998) studied regional trends in annual global irradiance based on data from the Global Energy Balance Archive (GEBA) on a $2.5^{\circ} \times 2.5^{\circ}$ resolution. The results show that significant reductions have taken place over large regions of Africa, Asia, Europe and North America, with an averaged relative decrease in $2 \%$ per decade. A new term (global dimming) was coined to label this fact (Stanhill, 2001).

Such a decrease has received prominent attention due to its profound influence on surface temperature, evaporation, the hydrological cycle, and ecosystems. Wild et al. (2005) found that the decreasing trends did not persist into the 1990s. Instead, a pronounced increasing trend has been observed since the late 1980s, on the basis of the analysis of the newly available surface observations. The reversal in solar insolation was also revealed by satellite-based estimates (Pinker et al., 2005). Both the increase in atmospheric transmission under clear- and all-sky conditions accounted partly for the reversal.

Surface solar insolation declined apparently over much of China, especially in the eastern half of country, where most stations showed more than a $6 \%$ reduction per decade $(\mathrm{Li}$ et al., 1998; Che et al., 2005), although this would not be expected if the decreases in cloud cover over much of China were considered (Kaiser, 1998).

The first purpose of this study is to report on a remarkable decline in solar radiation from 1961 to 2000 in China. The second is to focus on the solar radiation trend in the last 20 years. The potential causes are examined on the basis of visibility data and statistical analysis. The effects of solar radiation decline on climate are discussed in the end. 


\section{Site, instrument, data and methodology}

A national thermopile pyranometer network that consistsd of more than 100 stations across China has been established from the end of the 1950s. Forty-six stations are recognized to be first class by the Chinese Meteorological Administration (CMA). Standardized calibration and careful maintenance are regularly performed. The measurement accuracy for global radiation is estimated to be on the order of $3 \%$ and the measurement uncertainty is estimated to be $10 \%$ for diffuse radiation (Ma, 1998). Long-term and continuous measurements of global and diffuse irradiances are guaranteed only in the first-class stations, so we will report results from first-class stations. Monthly radiation data in a few first-class stations have been submitted to the Global Energy Balance Archive (GEBA) at the end of the 1980s, which were employed by Wild (2005).

The global and diffuse irradiances are measured by similar thermopile pyranometers as those used in FSU (Abakumova, et al., 1996), both without and with a shadow-band device, respectively. Shadow-band correction factors to the diffuse radiation data, recommended by World Meteorology Organization (WMO) are applied to the diffuse irradiance measurements (Wang, 1993). Direct irradiance on a horizontal surface is calculated as the difference between global and diffuse irradiance. The regular calibration of instruments is performed through inter comparison with the secondary standard instruments every second year (Ma, et al., 1998). Daily global, diffuse and direct irradiance are archived at the Climate Data Center of CMA (CDC/CMA). Detailed descriptions to 42 first-class stations are presented in Table 1, including location, and land use (four stations have been eliminated in the analysis due to their short-term duration in operation). Note that most of the stations are located in urban or suburb regions. This is actually not only peculiar to China, as it happens in other parts of the world, too. What we should keep in mind is that the trends might have a little bias. The altitude of most stations over Western China is more than $1 \mathrm{~km}$ because of the high elevation there. The altitude of eastern stations is close to the sea level.

Daily solar irradiances (global, direct, and diffuse) in each station are summed over each month; thereby, the seasonal and annual averages are obtained. The linear trend analysis is performed on seasonal and annual values and a t-test is used to determine whether the slope of the fitted trend model is significantly different from zero. When the significance level reached $95 \%$ or greater, the trend was deemed statistically significant. For each station, decadal trends (with physical unit, i.e. $\mathrm{W} / \mathrm{m}^{2}$ ) and the relative percentage change per decade, were calculated (Power, 2003).

\section{Secular trends in solar irradiance}

Decadal percentage changes in annually global, direct, and diffuse irradiance in each station are presented in Fig. 1 (up: global; middle: direct; bottom: diffuse). The trend magni- tudes are represented by different symbols and the station trend indicators with circles around them indicate indicate that the trend is significant at the $95 \%$ confidence level. It is apparent that the observed decreasing tendency in global and direct irradiance is of national character. The decreasing trend in global irradiance was observed at 37 sites. The magnitudes range from $-9.5 \%$ to $-0.6 \%$ per decade. A national average decrease is $-3.3 \%$ per decade. As for direct irradiance, the decreasing tendency was derived in nearly all sites except one. The trend ranges from $-0.8 \%$ to $-19.0 \%$ and the national mean is $-8.6 \%$ per decade. It is interesting to note that the largest decline in global and direct irradiance primarily appeared in Eastern China (east of about $100^{\circ} \mathrm{E}$ and south of about $40^{\circ} \mathrm{N}$ ), where aerosol loading is heavy and has been shown to increase significantly (Luo et al., 2001).

Diffuse irradiance demonstrated quite a different picture. Diffuse irradiance decreases in 24 sites. The rest have shown an increasing trend of no more than $9.5 \%$. All-China time series of annual departures (derived from the weighted average of the individual series by cosine of site latitude from the 1960-2000 means of global, direct and diffuse irradiance) were computed and are shown in Fig. 2 (top: Global; middle: Direct; bottom: Diffuse). It is obvious that for China as a whole, annual means of global and direct irradiance decrease remarkably and persistently. More interesting is that the time series of global and direct radiation show a dramatic dropoff since 1978, when a rapid increase in AOT at $750 \mathrm{~nm}$ has been observed, as a result of the rapid economic expansion and population growth (Luo et al., 2001). Seasonal trends in global and direct irradiance (not shown) were found to be quite similar to that of the annual trends. A much smaller trend is derived for diffuse radiation. The effect of volcano eruption on diffuse radiation is obvious, for example, the diffuse irradiance in 1982, 1983 and 1992 is larger than the 40year average by more than $3.5 \%$. This can be attributed to the El Chinchon eruption in April of 1982 and the Pinatubo eruption in June of 1991.

As shown in Fig. 2, the decreasing trends in solar radiation in China did not persist into the 1990s. Instead, more solar radiation (global and direct) was transmitted to the ground in the 1990s compared to the 1980s. Solar radiation in China has leveled off since the late 1980s.

\section{Trend analysis of sunshine duration, total rainy days}

The sunshine duration, defined as the amount of time when solar direct irradiance exceeds a specified threshold, is frequently used as a substitute for radiation measurement. If the amount of surface irradiance has changed, then the same change would be expected in sunshine duration. The annual and seasonal sunshine duration trends over 192 meteorological stations across China are computed, in order to check the consistency of the climatic change in China. Meteorological stations in China have employed the CampbellStokes Sunshine Recorder since 1954. The quantity measured by a sunshine recorder is the amount of time, usually 
Table 1. Detailed description of 42 Chinese first-class pyranometer stations presented in the analysis. The title, location, altitude, land use, mean and one standard deviation of solar radiation $\left(\mathrm{W} / \mathrm{m}^{2}\right)$ and its trend $(\%$ per decade) are given in each column, respectively.

\begin{tabular}{|c|c|c|c|c|c|c|c|}
\hline Station & $\operatorname{Lat}\left({ }^{\circ}\right)$ & $\operatorname{Lon}\left({ }^{\circ}\right)$ & Alt (m) & Land Use & Mean & STD & Trend \\
\hline Haikou & 20.03 & 110.35 & 14 & light industry & 160.89 & 15.102 & -2.18 \\
\hline Jinghong & 22 & 100.8 & 553 & Agriculture & 177.87 & 10.479 & -0.58 \\
\hline Nanning & 22.82 & 108.35 & 73 & light industry & 145.16 & 11.593 & -2.17 \\
\hline Guangzhou & 23.13 & 113.32 & 7 & industry & 134.85 & 12.73 & -5.17 \\
\hline Shantou & 23.4 & 116.68 & 1 & light industry & 158.95 & 15.74 & -2.52 \\
\hline Kunming & 25.02 & 102.68 & 1891 & Light industry & 171.14 & 10.644 & 0.54 \\
\hline Ganzhou & 25.85 & 114.95 & 124 & Light industry & 144.86 & 9.571 & -2.31 \\
\hline Fuzhou & 26.08 & 119.28 & 84 & Light industry & 139.93 & 12.607 & -2.25 \\
\hline Guiyang & 26.58 & 106.72 & 1074 & Industry & 116.34 & 12.637 & -3.98 \\
\hline Zunyi & 27.68 & 106.92 & 849 & Light industry & 107.52 & 12.585 & -7.94 \\
\hline Nanchang & 28.6 & 115.92 & 48 & Light industry & 143.11 & 15.245 & -6.40 \\
\hline Chongqing & 29.85 & 106.43 & 259 & Industry & 106.77 & 11.251 & -9.53 \\
\hline Hangzhou & 30.23 & 120.17 & 42 & Light industry & 134.1 & 12.791 & -2.51 \\
\hline Wuhan & 30.62 & 114.13 & 23 & Industry & 142.09 & 21.946 & -7.13 \\
\hline Chengdu & 30.67 & 104.02 & 506 & Industry & 112.6 & 11.88 & -6.55 \\
\hline Yichang & 30.7 & 111.3 & 133 & Light industry & 125.78 & 13.285 & -3.59 \\
\hline Changdu & 31.15 & 97.17 & 3306 & Agriculture & 192.78 & 19.604 & -2.78 \\
\hline Shanghai & 31.17 & 121.43 & 5 & Industry & 146.66 & 10.027 & -5.24 \\
\hline Hefei & 31.87 & 117.23 & 28 & Light industry & 139.4 & 15.836 & -4.97 \\
\hline Nanjing & 32 & 118.8 & 9 & Industry & 113.38 & 7.6499 & -8.60 \\
\hline Xi'an & 34.3 & 108.93 & 398 & Industry & 142.3 & 13.04 & -4.31 \\
\hline Zhengzhou & 34.72 & 113.65 & 110 & Industry & 155.37 & 10.672 & -0.80 \\
\hline Langzhou & 36.05 & 103.88 & 1517 & industry & 168.12 & 13.247 & -3.00 \\
\hline Xining & 36.62 & 101.77 & 2261 & Industry & 185.19 & 16.919 & -4.37 \\
\hline Jinan & 36.68 & 116.98 & 52 & Industry & 156.92 & 12.386 & -4.13 \\
\hline Hetian & 37.13 & 79.93 & 1374 & Agriculture & 187.47 & 10.072 & -1.53 \\
\hline Yantai & 37.53 & 121.4 & 47 & Light industry & 154.42 & 12.596 & 0.53 \\
\hline Taiyuan & 37.78 & 112.55 & 778 & Industry & 168.94 & 11.829 & -3.95 \\
\hline Yinchuan & 38.48 & 106.22 & 1111 & Industry & 191.61 & 7.1921 & -1.79 \\
\hline Ruoqiang & 39.03 & 88.17 & 888 & Agriculture & 195.89 & 10.148 & 0.14 \\
\hline Tianjin & 39.08 & 117.07 & 3 & Industry & 162.83 & 14.901 & -4.30 \\
\hline Kashi & 39.47 & 75.98 & 1289 & Agriculture & 182.58 & 14.085 & -2.44 \\
\hline Beijing & 39.93 & 116.28 & 54 & Industry & 168.92 & 14.002 & -5.17 \\
\hline Dunhuang & 40.15 & 94.68 & 1139 & Agriculture & 204.18 & 8.4197 & -1.28 \\
\hline Shenyang & 41.73 & 123.45 & 43 & Industry & 156.42 & 11.744 & -3.33 \\
\hline Kuche & 41.8 & 82.9 & 1073 & Agriculture & 186.69 & 8.5867 & -3.96 \\
\hline Hami & 42.82 & 93.52 & 737 & Agriculture & 200.77 & 6.9269 & -1.94 \\
\hline Ulumuqi & 43.78 & 87.62 & 918 & Industry & 164.6 & 9.785 & -3.30 \\
\hline Changchun & 43.9 & 125.22 & 237 & Industry & 158.72 & 10.083 & -0.60 \\
\hline Haerbin & 45.75 & 126.77 & 142 & Industry & 150.21 & 10.497 & 0.20 \\
\hline Jiamusi & 46.77 & 130.28 & 81 & Industry & 144.24 & 16.941 & 0.13 \\
\hline Aletai & 47.73 & 88.08 & 735 & Agriculture & 175.18 & 7.1342 & -1.87 \\
\hline
\end{tabular}

expressed to the nearest $0.1 \mathrm{~h}$, in which the direct solar radiation is of sufficient intensity $\left(120 \mathrm{~W} / \mathrm{m}^{2}\right)$ to activate the recorder (Kaiser and Qian, 2002). Figure 3 presents the spatial distribution of trends in the sunshine duration. Nearly $85 \%$ of the stations showed a decreasing trend and a large decrease occurred in Eastern China (east of about $100^{\circ} \mathrm{E}$ and south of about $40^{\circ} \mathrm{N}$ ). A few stations over Western and Northern China have shown an increasing trend but most are not statistically significant. The annual time series of departures from the weighted average of the individual sunshine 

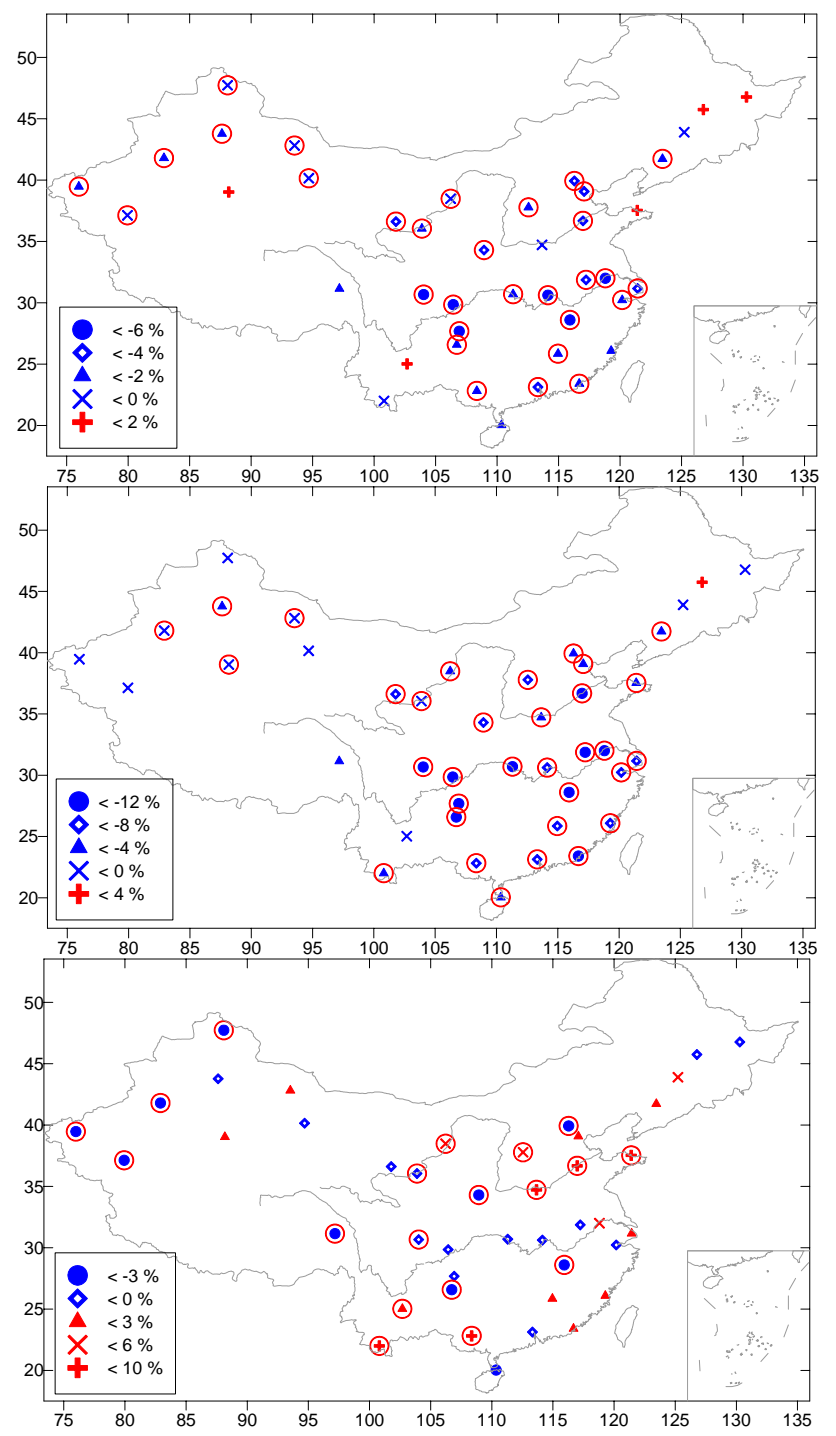

Fig. 1. Trends in annual global irradiance (up), direct irradiance (middle) and diffuse irradiance (bottom) at 42 first-class radiation stations. They are derived from radiation data during 1961 to 2000. The magnitude is demonstrated by different symbols. Stations with indicators with circles around them are significant at the $95 \%$ confidence level.

duration series by cosine of the site latitude are computed (not shown). A significant decline in the sunshine duration is apparent and also the drop-off begins in 1978. More importantly, the sunshine leveled off in the 1990s.

It is speculated that the two most probable causes for the reported "global dimming" are changes in the amount of cloud cover and aerosol (Stanhill, 2001; Liepert, et al., 2002). As a matter of fact, "global dimming" that happened in FSU, the United States and Australia is consistent with the cloud amount increase that is deduced from the various national cloud data sets. This indicates that the cloud amount increase may account for, at least, part of the observed declines in solar radiation in these regions. The question which arises here is whether this conclusion holds in China. If not, the subse-

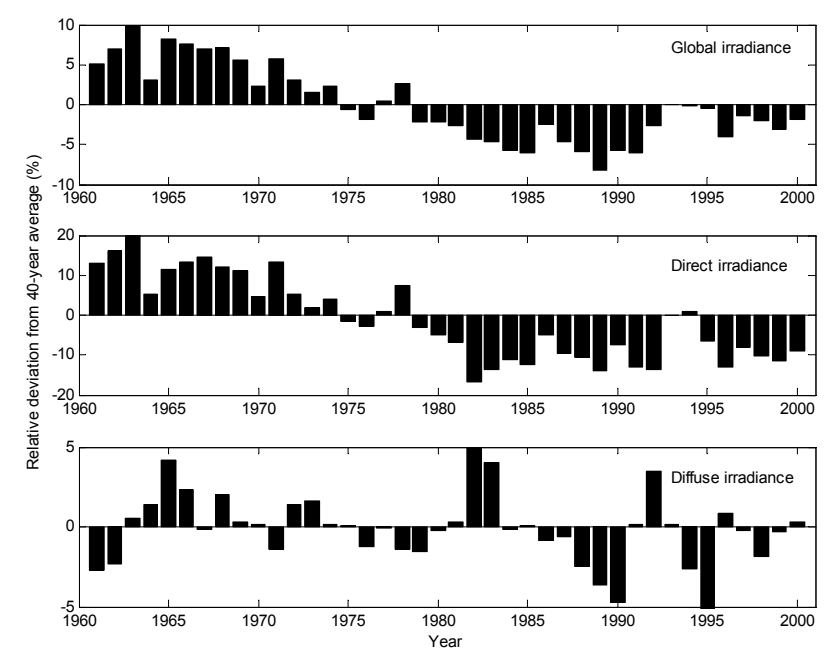

Fig. 2. Time series of all-China annual relative departures from 40year averages in global (up), direct (middle) and diffuse (bottom) for 1961-2000. The series is the mean of the weighted individual departure in each station by the cosine of its latitude.

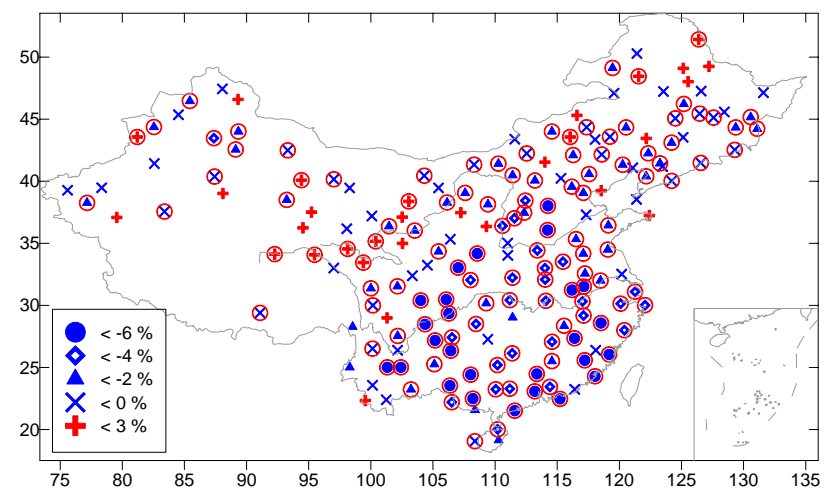

Fig. 3. The same as Fig. 1, but for annual mean sunshine duration at 192 meteorological stations. A significant decline in sunshine over much of China is apparent.

quent question is, what other factors resulted in the decline of solar radiation in China?

Kaiser (1998) reported that the cloud amount decreased by $1-3 \%$ per decade in most regions of China. The result was derived from the analysis of surface-based cloud amount observations across China. The updated analysis of related variables to cloud amount, such as relative humidity, surface water vapor pressure and surface air pressure, has shown physically consistent trends over China which make sense in terms of the cloud amount trend (Kaiser, 2000). A rainy day is a good substitute for the cloud amount, as suggested by Wang et al. (1993) who found a good relation between the two variables in China.

Next, trends in total rainy days are analyzed and presented in Fig. 4. It is evident that the annual number of rainy days decreased over much of China, except in the western region, where an increasing trend less than $3 \%$ per decade was 
observed in a few stations. This spatial pattern is consistent with that of the precipitation amount and the cloud amount in China (Zhai, et al., 1997; Kaiser, 2000). The agreement indicates that there is little probability that the cloud amount increased in China.

A decreasing cloud amount would be expected to result in increasing sunlight to the ground; however, it is apparent that the observed same trends in total rainy days (cloud amount) and solar irradiance in China violate this expectation. Actually, even a positive relation between rainy days and solar irradiance (total and direct) were found in a few stations, which is mostly the result from the same trends in both parameters. The fact that the downward trends in rainy days and cloud amount are observed over much of China suggests that the cloud amount is not a primary cause for the significant decrease in solar radiation.

\section{Trend analysis of visibility}

Since the cloud amount has been verified to exert less of an influence on the secular trend in solar radiation, it is natural to question what other factors could cause the significant decreasing trend in solar radiation. One possible factor is aerosol. Next, we will check whether aerosol loading has been increasing and whether it plays an important role in the observed variation of solar radiation.

An increase in aerosol particles is expected to enhance the scattering and absorption of incoming solar radiation and thus impair visibility. So, we will use visibility data (also from CDC/CMA, 87 sites) for detecting their trend, using the same method. Visibility is graded by 10 classes, varying from 0 to 9 . They are corresponding to visibility less than $0.05,0.2,0.5,1.0,2.0,4.0,10.0,20.0,50.0 \mathrm{~km}$ and infinity, respectively. We define the visibility larger than $20.0 \mathrm{~km}$ as good visibility. The spatial distribution of trends is presented in Fig. 5. Most sites located in Western China showed an increasing trend. The surface data analysis showed that dust storms in Western China decreased during the last 40 years. Actually, visibility less than $20.0 \mathrm{~km}$ in Western China is mainly produced by dust weather. As a result, one would expect an increase in visibility there. Note that the occurrence of good visibility decreases significantly over the eastern part of China. It decreases more than $20 \%$ per decade in most sites. The decrease in visibility indicates that aerosol loading does increase, at least, in Eastern China. It was reported that the $\mathrm{SO}_{2}$ (the precursor to sulfate aerosol) emission amount in China has steadily increased by a factor of approximately five during the past half century. The average sulfur emission amount for China was 3.8, 7.0, 12.2 and $18.8 \mathrm{Tg} \mathrm{\textrm {SO } _ { 2 }}$ per year, for the 1960s, 1970s, 1980s, and 1990-1997 (Ren et al., 1997). Note that most industries and populations in China are located in the eastern half of the country; this fact and the prevailing westerly winds would tend to result in anthropogenic aerosols mainly concentrated on this region.

An increase in the amount of atmosphere aerosol is generally expected to result in less direct irradiance to the ground.

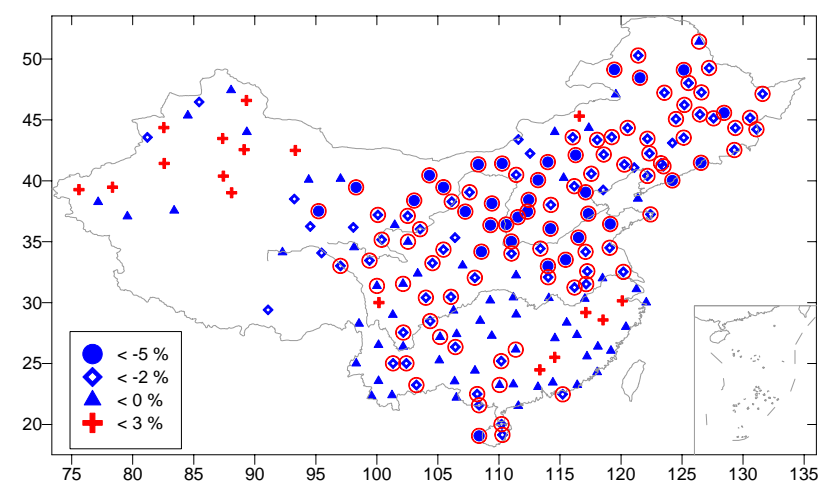

Fig. 4. The same as Fig. 1, but for annual rainy days at 192 meteorological stations. The decline in rainy days over much of China is in agreement with the analysis of the cloud amount data (Kaiser, 1998).

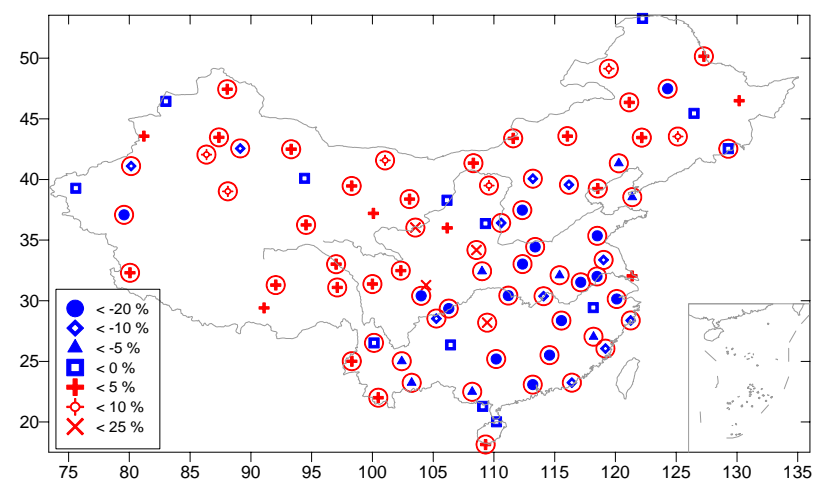

Fig. 5. The same as Fig. 1, but for good visibility (visibility greater than $20.0 \mathrm{~km}$ ) analysis at 87 stations. The significant decline in good visibility is evident in eastern part of China, where most stations showed more than a $20 \%$ decline per decade in the occurrence of good visibility. The increase in good visibility in Western China is attributed to a remarkable decrease in dust storms there.

A fraction of the impairment of direct irradiance is scattered to the surface, so diffuse irradiance would be expected to increase with aerosol loading, if aerosol absorption is weak. The global radiation will decrease as aerosol loading increases, because the impairment of its direct component cannot be offset completely by its diffuse component. Our knowledge about aerosol absorption in China is still limited. A few preliminary results showed aerosol absorption is strong, for example, aerosol single scattering albedo at $550 \mathrm{~nm}$ in Beijing is about 0.81 (Bergin et al., 2001). This is probably the cause for the decrease in diffuse radiation at a few sites. Given the role of aerosols as agents of radiative forcing, variability in aerosols in China may be responsible for, at least, part of observed changes in solar radiation to the Earth's surface. 

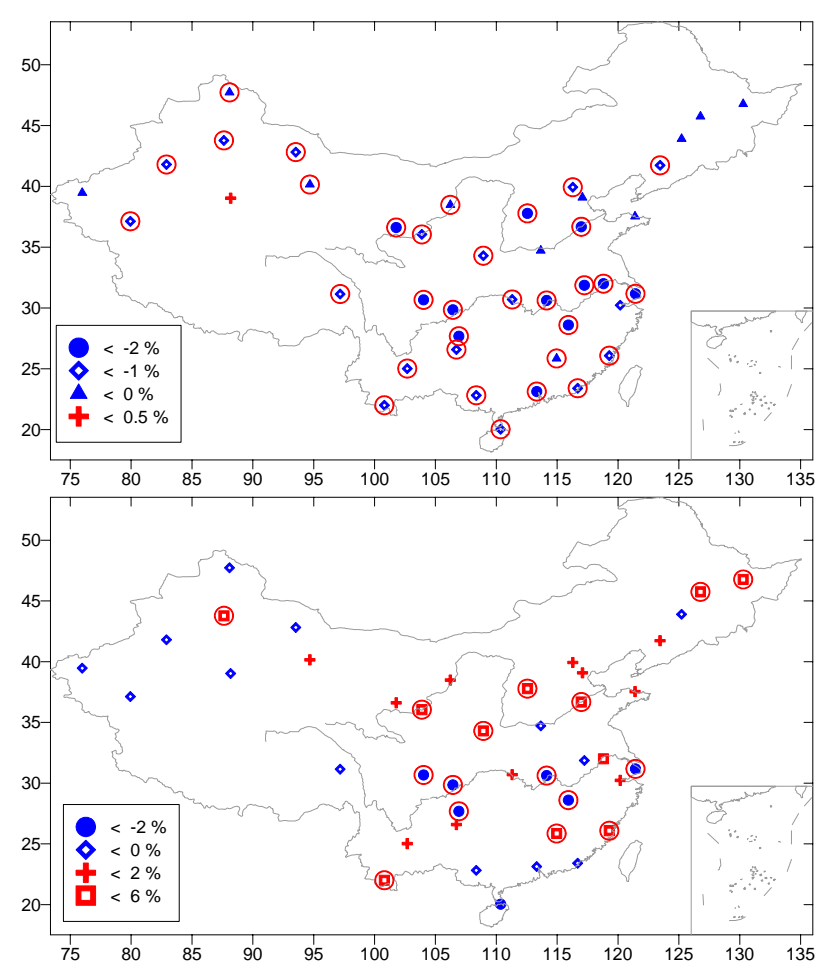

Fig. 6. The same as Fig. 1, but for the ratio of surface global radiation to solar radiation at the top of the atmosphere under clear-sky conditions (up) and under cloudy-sky conditions (bottom). A clear sky and a cloud sky are defined when the accumulation frequency of the ratio is greater than $70 \%$ and less than $30 \%$, respectively.

\section{A statistical analysis of solar radiation variation un- der clear conditions}

Little information about daily sky conditions is available, which prevent us in distinguishing directly the contributions of cloud and aerosol to the decline in solar radiation. Next, we will employ a statistical method introduced by Liepert (1994) to explain indirectly aerosol's role. A brief introduction to the method is presented here. First, the ratio of daily global irradiance to solar radiation at the top of the atmosphere is computed, in order to eliminate the seasonal variation of data. Clear-sky is characterized by high ratios, whereas a; cloudy-sky is indicated by low ratios. Second, an accumulation frequency analysis is carried out on the basis of whole daily ratios in each site. The thresholds used to define a clear -sky and a cloudy sky are ratios corresponding to the accumulation frequency greater than $70 \%$ and less than $30 \%$, respectively. New time series are created accordingly, i.e. annual mean of ratios less than the threshold for a cloudy sky and greater than the threshold for a clear sky, respectively. Last, trend analysis is then carried out. Figure 6 presents the spatial distribution of trends derived under a clear sky (up) and a cloud ky conditions (bottom). Nearly half of the trends under cloud conditions are upward and the remaining are downward. It is interesting to note that the ratios decrease under clear-sky conditions over much of China.
This is indicative of a surface solar radiation decline under this condition. Since long-term variations in aerosol loading have a remarkable effect on global solar radiation, especially on clear days, it is therefore reasonable to reach the conclusion that the increase in aerosol loading should be one of the principle reasons for surface solar radiation decline in China.

\section{Conclusions and discussion}

Trends in solar irradiance (global, direct and diffuse) in 42 first-class pyranometer stations in China are computed for the last 40 years. Trends in climatic parameters closely related to solar energy, such as sunshine duration, rainy days and visibility, are analyzed in order to present supporting material for, or indicate the potential causes of, the observed trends in solar radiation.

A significant decline in global and direct irradiance is apparent over much of China, especially in the eastern half of the country. Most of the declines in global and direct irradiance have occurred since 1978, when anthropogenic aerosols increased, remarkably and also dramatic climate change occurred, such as the rapid increase in global temperature, and the shift in the ENSO phenomenon at about the same time from the more frequent El Nino episodes to the more frequent La Nina episodes (Kaiser, 2000). Diffuse irradiance has shown a much less pronounced trend and a more complex spatial pattern. The trends in sunshine duration are consistent with that of solar irradiance in the spatial and temporal pattern.

Most trends in rainy days are negative, which is in agreement with the trends in cloud amount. Consequently, one would expected that solar irradiance to the ground should have increased in China as a result of the decrease in cloud amount. By inference it seems that the long-term variation in cloud amount in China does not support the decline in solar irradiance. But this is not to say that clouds have no effect on the surface radiation decline. To completely characterize cloud effects on radiation, except its amount, we should have full knowledge of its type (low, middle and high clouds) and physical and radiative properties (size, optical thickness). The unavailability of these data prevents us from completely rejecting the influence of clouds on the trends in surface solar radiation.

The analysis of visibility data showed that the frequency of good visibility (visibility greater than $20 \mathrm{~km}$ ) decreased significantly in the eastern part of China. This is a good indictor for the rapid increase in aerosol loading there. Given the role of aerosols as agents of radiative forcing, variability in aerosols may be responsible for, at least, part of the observed declines in surface solar radiation. Aerosol is long recognized to result in less solar radiation to the ground through direct scattering and absorption of solar irradiance, or via its indirect effects, i.e. aerosol, as the cloud condensation nuclei $(\mathrm{CCN})$, may change cloud microphysical and optical properties (the first indirect effect), and cloud cover and lifetime (the second indirect effect), thus leading to less solar 


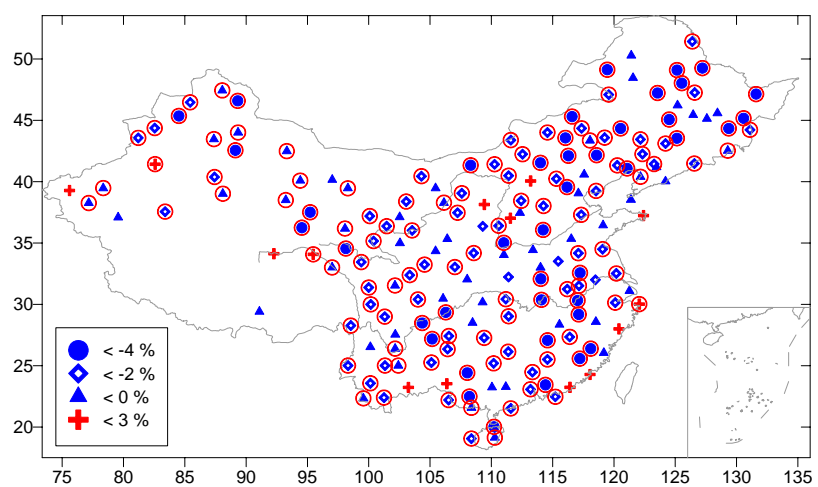

Fig. 7. The same as Fig. 1, but for daily temperature range (DTR) analysis at 192 stations. The significant decline in DTR is obvious over much of China, generally due to larger increases in the minimum temperatures compared to maximum temperatures. As a matter of fact, a decreasing trend in maximum temperature (not shown) is observed in the eastern part of China, where visibility decreased greatly.

irradiance to the ground (Charlson, et al., 1992; Ramanathan, et al., 2001). The decrease in aerosol-induced solar transmission under a clear sky was demonstrated by a statistical method.

A few intriguing regional climate changes have occurred in China, such as moderate cooling in low regions of the Yangtze River during the past 50 years and the increased summer floods in South China and the increased drought in North China. It is suggested that they are closely related to the increase in aerosol emission (Li et al., 1995; Qian and Giorgi, 2000; Xu, 2001; Menon et al., 2002). The decreasing diurnal temperature range (DTR) has been observed over the world (Karl et al., 1993). Similarly, DTR decreases over much of China (see Fig. 7). The decrease in DTR is due to larger increases in the minimum temperatures compared to maximum temperatures. As a matter of fact, a decreasing trend in maximum temperature (not shown) is observed in the eastern part of China, where good visibility was shown to decline greatly. The decrease in DTR is a further independent check for the observed reduction in global solar irradiance (Roderick and Farquhar, 2002). What we would like to emphasize is that the decrease in DTR is largely attributed to the increase in cloud cover in FSU and the United States, but this does not hold in China. The fact that the cloud amount and the number of rainy days declined implies that the increase in aerosols is one of the potential causes for the decreased DTR. Moreover, note that the same tendency in the number of rainy days and the visibility in the eastern part of China has been derived in the last 40 years. Whether this implied that aerosol did play an important role in precipitation through its direct and indirect effects is still unclear. Answers to this question are fundamental for developing confidence in the global and regional projection of a future climate scenario. Further researches on aerosol properties and its role in the climate system is urgently required.
Acknowledgements. The author thanks for CDC/CMA providing radiation data. The research is partly funded by NSFC grants 40305002 and 40520120071. Special thanks go out to two anonymous reviewers for their critical comments and suggestions.

Topical Editor F. D'Andréa thanks M. Wendisch and another referee for their help in evaluating this paper.

\section{References}

Abakumova, G. M.: Evaluation of long-term changes in radiation, cloudiness, and surface temperature on territory of the former Soviet Union, J. Climate, 9, 1319-1327, 1996.

Bergin, M. H., Cass, G. R. J., Xu, C., Fang, L. M., and Zeng, L. M., et al.: Aerosol radiative, physical and chemical properties in Beijing during June 1999, J. Geophys. Res. 106, 17 969-17980, 2001.

Charlson, R. J., Schwartz, S. E., Hales, J. M., Cess, D., Coakley, J. A., and Hansen, J. E.: Climate forcing by anthropogenic aerosols, Science, 255, 423-430, 1992.

Che, H. Z., Shi, G. Y., Zhang, X. Y., Arimoto, R., Zhao, J. Q., Xu, L., Wang, B., and Chen, Z. H.: Analysis of 40 years of solar radiation data from China, 1961-2000, Geophys. Res. Letts., 32 , L06803, doi:10.1029/2004GL022322, 2005.

Gilgen, H. and Wild, M.: Means and trends of short-wave irradiance at the surface estimated from global energy balance archive data, J. Climate, 11, 2042-2061, 1998.

Kaiser, D. P.: Analysis of total cloud amount over China, 19511994, Geophys. Res. Lett., 25, 3599-3602, 1998.

Kaiser, D. P.: Decreasing cloudiness over China: an updated analysis examining additional variables, Geophys. Res. Lett., 27, 2193-2196, 2000.

Kaiser, D. P. and Qian, Y.: Decreasing trends in sunshine duration over China for 1954-1998: indication of increased haze pollution?, Geophys. Res. Lett., 21, 2042, doi:10.1029/2002GL016057, 2002.

Karl, T. R., Jones, P. D., Knight, R. W., Kukla, G., Plummer, N., Razuvayev, V., Gallo, K. P., Lindseay, J., Charlson, R. J., and Peterson, T. C.: A New Perspective on Recent Global Warming: Asymmetric Trends of Daily Maximum and Minimum Temperature. Bulletin of the American Meteorological Society, 74, 1007 1023, 1993.

Li, X. W., Zhou, X. J., and Li, W. L.: The cooling of Sichuan province in recent 40 years and its probable mechanism, Acta. Meteo. Sinica, 9, 57-68, 1995.

Li, X. W. and Zhou X. J.: Analysis of the solar radiation variation of the China in recent 30 years, Quart. J. Appl. Meteo., 9, 24-31, 1998.

Liepert, G. G.: Solar radiation in Germany - Observed trends and an assessment of their causes, Part 1. regional approach, Contr. Atmos. Physics., 67, 15-29, 1994.

Liepert, B. G. and Kukla, G. J.: Decline in solar radiation with increased horizontal variability in Germany between 1964-1990, J. Climate, 2391-2401, 1997.

Liepert, B. G. and Tegen, I.: Multi-decadal solar radiation trends in the United States and Germany and direct tropospheric aerosol forcing, J. Geophys. Res., 107, doi:10.1029/2001JD000760, 2002.

Luo, Y. F., Zou, X. J., Li, W. L., and He, Q.: Characteristics of the spatial distribution and yearly variation of aerosol optical depth over China in last 30 years, J. Geophys. Res., 106, 14501 14 514, 2001. 
Ma, Y. Z., Liu, X. N., and Xu, S.: The description of Chinese radiation data and their quality control procedures, Meteo. Sci., 2, 53-56, 1998.

Menon, S., Hansen, J. M., Nazarenko, L., and Luo, Y. F.: Climate effects of black carbon aerosols in China and India, Science, 297, 2250-223, 2002.

Pinker, R. T. B. and Zhang, E. G.: Do satellites detect trends in surface solar radiation? Science, 308, 850-854, 2005.

Power, H. C.: Trends in solar radiation over Germany and an assessment of the role of aerosols and sunshine duration, Theor. Appl. Climatol., 76, 47-63, 2003.

Qian Y. and Giorgi F.: Regional climatic effects of anthropogenic aerosols? The case of SouthWestern China, Geophys. Res. Lett., 27, 3521-3524, 2000.

Ren, Z. H., Jiang, Z. Y., Yang, X. X., and Gao, Q. X.: Research on the atmospheric transportation, deposition and mutual influence of interprovince of acid materials over China. Acid rain and its control issue in China, China Center of Advanced Sciences and Technology - World Laboratory workshop series, 78, 7596, 1997.

Ramanathan, V., Crutzen, P. J., Kiehl, J. T., and Rosenfeld, D.: Aerosols, climate, and the hydrological cycle, Science, 294, 2119-2124, 2001.

Roderick, M. L. and Farquhar, G. D.: The cause of decreased pan evaporation over the past 50 years, Sciences, 298, 1410-1411, 2002.
Stanhill, G. and Kalma, J. D.: Secular variation of global irradiance in Australia, Australian Meteoro. Mag., 43, 81-86, 1994.

Stanhill, G. and Ianetz, A.: Long term trends in, and spatial variation of global irradiance in Israel, Tellus, 49B, 112-122, 1996.

Stanhill, G. and Cohen, S.: Recent changes in solar irradiance in Antarctica, J. Climate, 10, 2078-2086, 1997.

Stanhill, G.: Long term trends in, and spatial variation of, solar irradiances in Ireland, Int. J. Climato. 18, 1015-1030, 1998.

Stanhill, G.: Global dimming: a review of the evidence for a widespread and significant reduction in global radiation with discussion of its probable causes and possible agricultural consequences, 107, 255-278, Agriculture and Forest Meteoro., 2001.

Wang B. Z.: Measurement of solar radiation and its standard, Chinese Science Press, Beijing, 143-149, 1993.

Wang, W. C., Zhang, Q. Y., Easterling, D. R., and Karl, T. R.: Beijing cloudiness since 1875, J. Climate, 6, 1921-1927, 1993.

Wild, M., Gilgen, H., Roesch, A., et al.: From Dimming to brightening: Decadal changes in solar radiation at Earth's surface, Science, 308, 847-850, 2005.

$\mathrm{Xu}, \mathrm{Q}$.: Abrupt change of the midsummer climate in central east China by the influence of atmospheric pollution, Atmos. Environ., 35, 5029-5040, 2001.

Zhai, P. M., Ren, F., and Zhang, Q.: Indicators of change for extreme precipitation in China, paper presented at workshop on indices and indicators for climate extreme, National Climatic Data Center, Asheville, North Carolina, 3-6 June, 1997. 